\title{
Türkiye'de ulusal ve yerel sürekli gözlem yapan sabit GNSS istasyonları ağlarının mevcut durumu, standartlar ve farklı ağların entegrasyonu
}

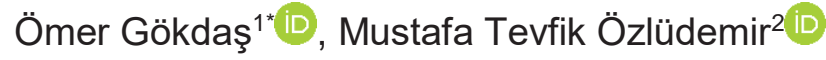 \\ ${ }^{1}$ Istanbul Su ve Kanalizasyon Idaresi (ISKI), Istanbul, Türkiye. \\ ${ }^{2}$ Istanbul Teknik Üniversitesi, Ayazağa Kampüsü, Inşaat Fakültesi, Geomatik Mühendisliği Bölümü, Maslak, Istanbul, Türkiye.
}

\begin{abstract}
Öz: Türkiye Ulusal Sabit GPS Ă̆g-Aktif (TUSAGA-Aktif) sistemi 2009 yllından başlayarak, günümüzde Türkiye'de konum belirlemede en

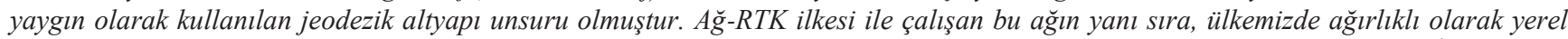
yönetimler ve sayıları az da olsa özel sektör kuruluşları tarafindan işletilen yerel Sürekli Gözlem Yapan Sabit GNSS Istasyonları (Continuously Operating Reference Stations, CORS) da mevcuttur. Ulusal ve yerel ölçekteki bu ağlar temel mühendislik çalışmalarının yanı sıra bilimsel amaçlı çalışmalarda da etkin olarak kullanılmaktadır. Yerel ağların ulusal TUSAGA-Aktif ăğ ile tanımlanacak standartlar ekseninde entegrasyonu ülkemiz jeodezi topluluğunun gündemine almasi gereken önemli bir konudur. Bu çallşmada farklı ülkelerde ulusal ve yerel düzeyde kurulan CORS ağlarına ve geliş̧tirilen standartlara iliş̧kin örnekler verilmiş, Türkiye'deki mevcut durum ele alınmış, yerel ağların bilimsel çalışmalara sağlayabileceği katkılar ortaya koyulmuştur. Ulusal ve yerel CORS ağlarının karşılaştırmalarına yönelik yapılmış olan çalışmalar incelenerek istasyonlar arası mesafenin konum belirlemedeki önemi vurgulanmış; bu hususta yerel ă̆ların ulusal ă̆a entegrasyonunun sağlayacă̆ı katkllar ifade edilmiştir. Bu çerçevede entegrasyon sonucunda baz mesafelerinin kısalmasının, dolayısıyla nokta yoğunluğunun artmasının ă̆ çözüm kalitesine olumlu katkısının olabileceğ değerlendirilmiştir. Bununla birlikte bu gelişmenin sağlanabilmesi için, ülkemizde yerel ölçekte kurulan CORS ă̆larının tasarım ve işletimi için standartların geliștirilmesi konusunun öncelikli olarak ele alınması gerektiği önerilmektedir.
\end{abstract}

Anahtar Sözcükler: GNSS, CORS ağları, Ağ RTK, Entegrasyon

\section{Current situation of national and local CORS networks in Turkey, standards and their integration}

Abstract: Turkey's National Permanent GNSS Network-Active (TUSAGA-Active) that has been started to use since 2009 is currently the most widely used geodetic infrastructure element in point positioning in Turkey. In addition to this network operating with the network RTK principle, there are also local Continuously Operating Reference Stations (CORS) networks in our country, which are mainly operated by local governments and a small number of private sector organizations. These networks, which are used nationally and locally, are used effectively in scientific studies as well as in basic engineering works. Integration of local networks in the axis of standards to be defined with the national TUSAGA-Active network is an important issue that should be on the agenda of our country's geodesy community. In this study, CORS networks established at national and local levels in different countries, and examples of the developed standards are given, the current situation in Turkey and contribution of local networks to the scientific studies are discussed. The studies conducted for the comparison of national and local CORS networks were examined, emphasizing the importance of distance between stations in determining the positioning. In this context, the contribution of local networks to the national network has been demonstrated. In this framework, it has been evaluated that shortening the baseline lengths as a result of integration and thus increasing the point density may contribute positively to the network solution quality. However, in order to achieve this development, it is recommended that the development of standards for the design and operation of CORS networks established locally in our country should be addressed with priority.

Keywords: GNSS, CORS networks, Network RTK, Integration 


\section{Giriş}

Günümüzde yaygın olarak kullanılan Sürekli Gözlem Yapan Sabit GNSS İstasyonları (Continuously Operating Reference Stations, CORS) ağlarından jeodezi, jeofizik ve ölçme gibi birçok disiplinde fayda sağlanmaktadır. Başta haritacılık olmak üzere aktif olarak kullanılan CORS ağlarının diğer alanlarda da kullanımı artış göstermektedir. CORS ağlarının uygulamadaki faydaları ülkelerin haritacılık kuruluşlarını, yerel yönetimleri ve özel sektörü CORS ağı kurma fikrine yöneltmiştir (Kahveci, 2009).

Dünyada yürütülen önde gelen CORS ağı projelerinden biri Amerika Birleşik Devletleri'nde (ABD) bulunmaktadır. 230'dan fazla organizasyon tarafından desteklenen CORS ağı 2000'den fazla aktif istasyona sahiptir ve genişlemeye devam etmektedir. Hizmet dışı bırakılmış istasyonlarla beraber bu sayı 2718'dir. ABD’nin Ulusal Jeodezik Ölçme Kuruluşu (National Geodetic Survey, NGS) farklı işletmeciler tarafından yönetilen bu ağlardan gelen verileri entegre ederek ülkede ve sınır bölgelerinde meteoroloji, uzay araştırmaları, jeofizik uygulamaları gibi konularda çeşitli araştırmalar yapmaktadır. ABD’deki çok organizasyonlu bu ağ hükümet, akademi ve özel sektörün işbirliği ile işletilmektedir. Tüm organizasyonlar verilerini NGS ile paylaşmakta, NGS ise tüm yaptığı analiz çalışmalarını ücretsiz olarak yayımlamaktadır (URL-1).

Başka bir örnek Japonya'da faaliyet sürdüren GEONET CORS ağıdır. ABD’deki örnekten farkı merkezi olarak işletilmesidir. $\mathrm{Bu}$ ağ Japonya'da Jeo-Mekansal Bilgi Otoritesi (Geospatial Information Authority of Japan, GSI) tarafindan işletilmekte, 1300’ü aşkın istasyona sahip olup genişlemeye devam etmektedir. Ağda istasyonlar arası mesafe ortalama 20 km’dir. Ağın temel kuruluş amacı, jeodezik çalışmalarda referans olarak kullanılması ve deprem hareketliliğinin izlenmesidir. Bunların dışında, navigasyon, meteoroloji, tsunami gözlemleri gibi alanlarda da kullanılmaktadır (Miyahara, 2016; Tsuji, Kawamoto, \& Abe, 2018).

Bir diğer örnek ise Almanya'dır. Bu ülkedeki CORS ağı için ABD’deki sisteme benzer bir yönetim benimsenmiştir. Almanya'daki 16 eyalet kendi CORS ağlarının tasarımı ve işletiminden sorumludur. Ayrıca Federal Almanya Cumhuriyeti eyaletlerinin araştırma idarelerinin çalışma grubu (Arbeitsgemeinschaft der Vermessungsverwaltungen der Länder der Bundesrepublik Deutschland, AdV) tüm ağlardan sorumludur. AdV kullanıcılar için farklı doğrulukta üç farklı ürün sunmaktadır. Toplamda 270 referans istasyonuna sahip bu ağın adı Uydu Konum Belirleme Servisi'dir (Satellite Positioning Service, SAPOS) (Schwieger, 2012; URL-2).

Diğer örneklere bakacak olursak, Birleşik Arap Emirlikleri (BAE)'nin Dubai mevcut olan DVRS CORS ağı 2002 yılında 5 istasyon ile faaliyete başlamıştır. Haritacılık uygulamalarında kullanılmaktadır. Mevcutta 17 istasyonu bulunmaktadır ve merkezi sunucusunda Geo++ yazılımı kullanılmaktadır (El-Mowafy, Fashir, Al Marzooqi, Al Habbai, \& Babiker, 2003; URL-3). Belçika'da faaliyet gösteren FLEPOS CORS ağının kurulumu 33 istasyon ile yapılmıştır. Mevcut durumda ise 45 adet istasyon sayısına ulaşmıştır. Merkezi yönetim tarafından işletilmektedir. Sunucuda Trimble firmasına ait CORS yazılımı bulunmaktadır (Yayla vd., 2020; URL-4). İsveç’te bulunan SWEPOS CORS ağı 1990'lı yılların başında Harita, Kadastro ve Tapu Dairesi tarafından Chalmers Teknoloji Üniversitesi ve Onsala Uzay Gözlem Evi iş birliğinde kurulmuştur. 472 adet istasyon sayısına sahip olan ağın istasyonlar arası mesafesi 10 - 70 kilometre aralığındadır (URL-5). Norveç’te bulunan SATREF/CPOS CORS ağı Norveç Haritalama Dairesi tarafından işletilmektedir. 270 adet istasyona sahiptir. Kullanıcı profili daha çok inşaat sektörüdür. Ölçme faaliyetlerinin dışında iyonosfer gözlemleri yapılarak iyonosferik etkinin radyo sinyallerine etkisi araştırılmaktadır (Follestad, Clausen, Moen, \& Jacobsen, 2021). Hollanda'da faaliyet gösteren NETPOS CORS ağı, Hollanda'nın jeodezi altyapısının temeli olan Aktif GNSS Referans Sistemi’nin (AGRS) sıklaştırılması ile oluşturulmuştur. 29 adet istasyona sahip olup Hollanda Kadastro Servisi tarafindan yönetilmektedir. Merkezi sunucuda 
Geo++ yazılımı kullanılmaktadır (URL-6). Birleşik Krallık'ta ulusal koordinat sistemine geçişi sağlayan ağ ise OS Net CORS ağıdır. Ağ 115 adet istasyona sahiptir. 1791 yılından itibaren faaliyetlerini sürdüren ülkenin Haritacılık Kuruluşu (Ordnance Survey) tarafindan yönetilmektedir (URL-7). Polonya'da mevcut bulunan ASG-EUSPOS CORS ağı ise Avrupa'ya ait olan konum belirleme sisteminin aktif bir jeodezik ağıdır. Polonya Jeodezi ve Kartografya Dairesi tarafından işletilmektedir. 2013 yılına kadar ülke genelinde tek olarak hizmet vermiştir. 2013 yılı itibari ile OS Net CORS ağına ek olarak ticari olarak yönetilen CORS ağları da oluşturulmuştur (SmartNet, TPINet, VRSNet) (Prochniewicz vd., 2020). Suudi Arabistan'da Haritacılık ve Jeouzamsal Bilgi Dairesi tarafından 209 istasyonlu KSA CORS ağı işletilmektedir. İstasyonlar arası mesafe diğer ağlara göre görece olarak fazladır (Abd Rabbou, Abdelazeem, \& Morsy, 2021; URL-8). Yeni Zelanda'nın ulusal CORS ağı ise 2002'de 3 istasyon ile faaliyete başlayıp mevcutta 39 adet istasyon sayısına ulaşan PositioNZ CORS ağıdır. İstasyonların 35'i Yeni Zelanda'da, 1 adeti Chatham Adası'nda, 3 adeti ise Antarktika'da bulunmaktadır (URL-9).

Tablo 1'de farklı coğrafyalardaki ülkelerde kurulmuş CORS ağı örnekleri verilmiştir. Tablo 1'de ülke isimleri, istasyon adlarının kısaltmaları ve istasyon sayıları gösterilmektedir. Ülkelere ait yüzölçümleri, kilometrekareye kaç adet istasyon düştüğü ve buna göre istasyonlar arası ortalama mesafeler belirtilmiştir.

Tablo 1'de sunulan sıralama istasyon sayılarına göre değil, ağların baz mesafelerine ya da istasyon yoğunluklarına dikkat edilerek düzenlenmiştir. Buna göre, ortalama baz mesafesinde verilen örnekler için Türkiye'nin görece düşük istasyon yoğunluğuna sahip ülkeler arasında olduğu görülmektedir. Tablo 1'de Türkiye'de mevcut olan CORS ağı Kuzey Kıbrıs Türk Cumhuriyeti’ni de (KKTC) kapsadığı için yüz ölçümü buna dikkat edilerek verilmiştir.

Tablo 1: Dünyada CORS ağı örnekleri.

\begin{tabular}{|c|c|c|c|c|c|}
\hline Ülke & A $\breve{g}$ Adı & İstasyon Sayısı & Yüz ölçümü (km²) & $\begin{array}{l}\text { İstasyon Yoğunluğu } \\
\left(\mathrm{km}^{2} / \text { istasyon sayısı) }\right.\end{array}$ & $\begin{array}{r}\text { Ortalama Baz } \\
\text { Uzunluğu (km) }\end{array}$ \\
\hline Dubai (BAE) & $\overline{\text { DVRS }}$ & 18 & 4114 & 229 & 15 \\
\hline Japonya & GEONET & $1300+$ & 377915 & 291 & 20 \\
\hline Belçika & FLEPOS & 45 & 30689 & 682 & 26 \\
\hline İsveç & SWEPOS & 472 & 450295 & 954 & 31 \\
\hline Almanya & SAPOS & 270 & 357386 & 1324 & 36 \\
\hline Norveç & SATREF/CPOS & 270 & 385207 & 1427 & 38 \\
\hline Hollanda & NETPOS & 29 & 41543 & 1433 & 38 \\
\hline Birleşik Krallık & OS Net & 115 & 242495 & 2109 & 46 \\
\hline Polonya & ASG-EUPOS & 127 & 312679 & 2462 & 50 \\
\hline $\mathrm{ABD}$ & NGS & $2000+$ & 9834000 & 4917 & 70 \\
\hline Türkiye & TUSAGA-Aktif & 159 & 786916 & 4949 & 70 \\
\hline Yeni Zelanda & PositioNZ & 39 & 268021 & 6872 & 83 \\
\hline S. Arabistan & KSA-CORS & 209 & 2150000 & 10287 & 101 \\
\hline
\end{tabular}

Şekil 1-5’te ise bu ağlara ilişkin istasyon dağılımlarını gösteren örnekler verilmiştir. 


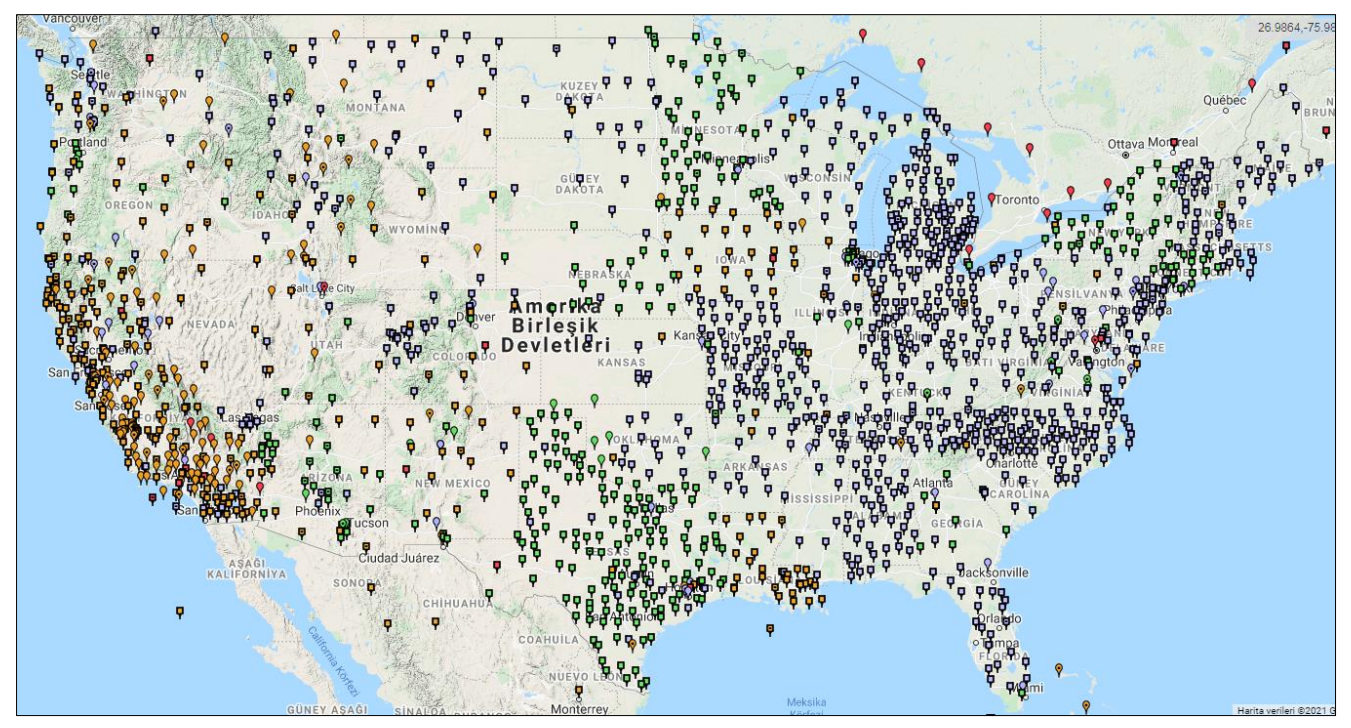

Şekil 1: NGS CORS ağı, ABD (URL-10).

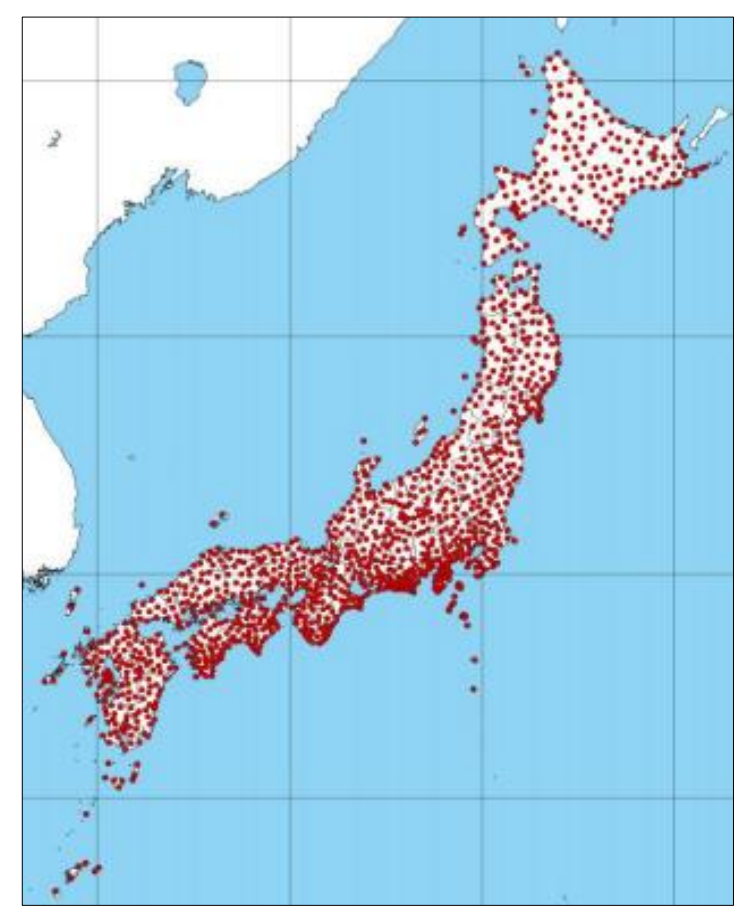

Şekil 2: GEONET CORS ağı, Japonya (URL-11). 


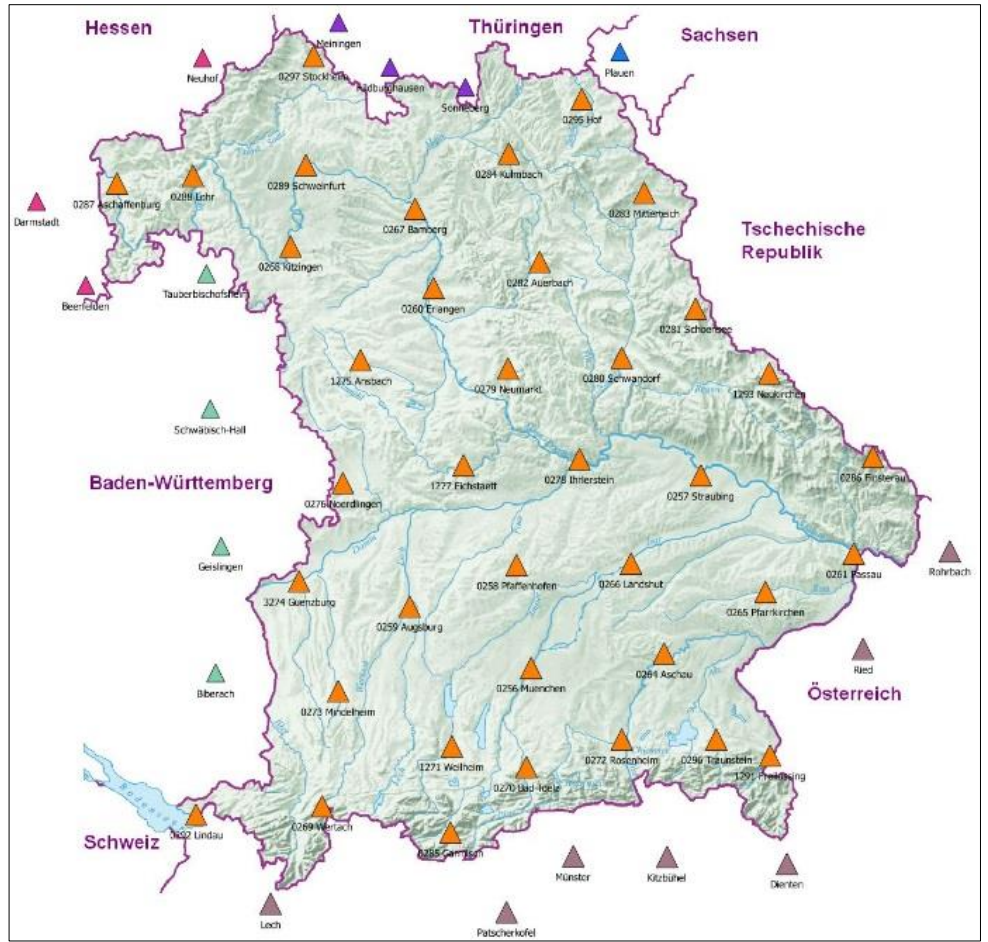

Şekil 3: SAPOS CORS ağı, Almanya Bavyera Eyaleti (URL-12).
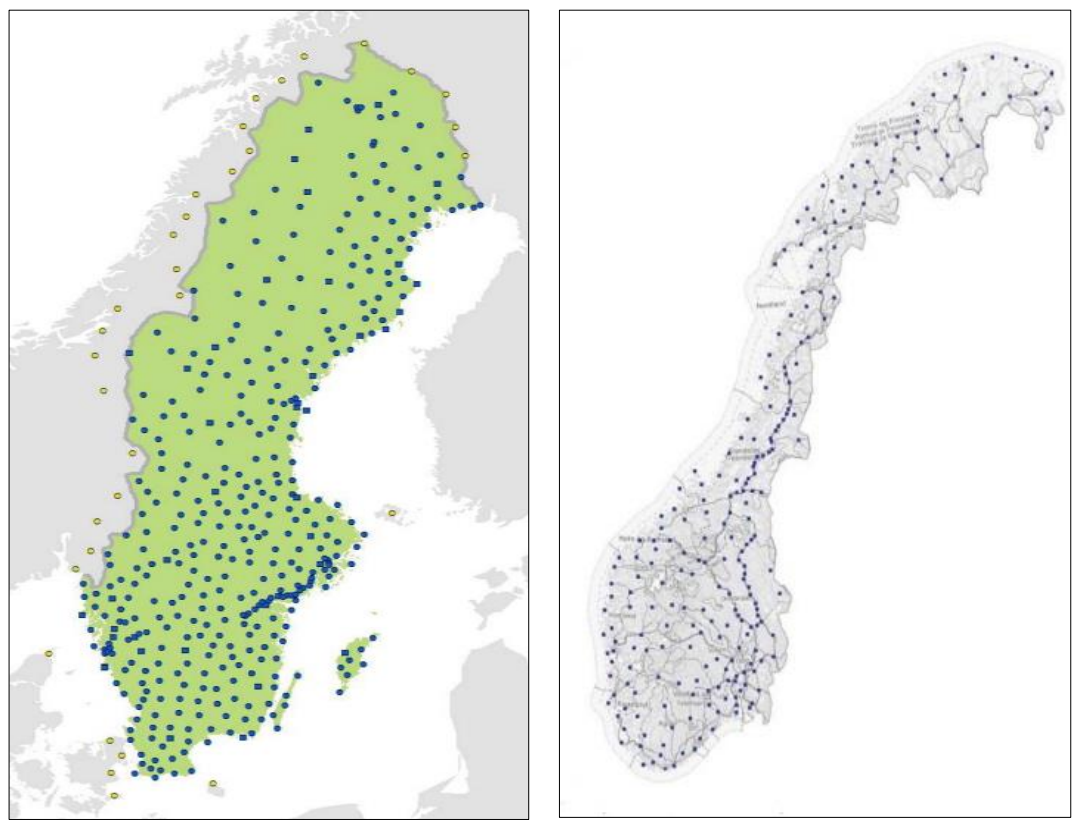

Şekil 4: (Solda) SWEPOS CORS ağı, Isveç (URL-13); (sağda) SATREF/CPOS CORS ağı, Norveç (URL-14). 


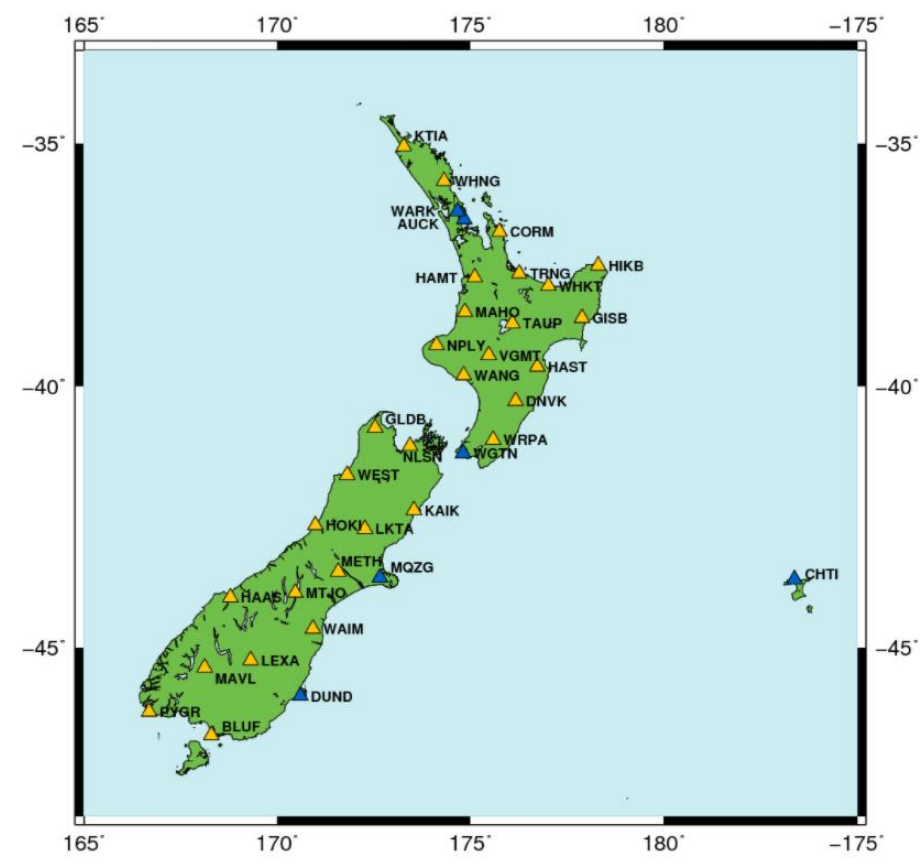

Şekil 5: PositioNZ CORS ağı, Yeni Zelanda (URL-9).

Bu çalı̧ma kapsamında, sözü edilen CORS ağlarının Türkiye'de ulusal ve yerel ölçekte kullanılan örneklerine yer verilmekte, CORS ağlarına ilişkin standartlar ele alınmakta ve yerel ağların ulusal CORS ağına entegrasyonunun önemi üzerinde durulmaktadır.

\section{2. Ülkemizdeki CORS Ağları}

\subsection{TUSAGA-Aktif Ağı}

Türkiye Bilimsel ve Teknolojik Araştırma Kurumu (TÜBİTAK) desteğiyle bir Kamu Araştırma Geliştirme (AR-GE) projesi kapsamında geliştirilen TUSAGA-Aktif GNSS ağı 2009 yılında tamamlanmıştır. Nisan 2006 tarihinde TÜBİTAK tarafından kabul edilen proje, 8 Mayıs 2006'dan itibaren 36 aylık bir çalışma sonucunda tamamlanmıştır (Uzel vd., 2011).

TUSAGA-Aktif ağının tasarımı aşamasında istasyonlar arası mesafenin ne olması gerektiğine ilişkin teknik ve bilimsel çevrelerde bir tartışma yaşanmış, çeşitli çalışmalar gerçekleştirilmiştir. Buna göre sonuçların, baz uzunluğunun ortalama 80 $100 \mathrm{~km}$ olacak şekilde yaklaşık 150 istasyon ile istenilen doğrulukta elde edilebileceği öngörülmüştür (Eren, Uzel, Gülal, Yıldırım, \& Cingöz, 2009). Bu tartışmalar sonucunda Türkiye genelinde ve KKTC'yi kapsayacak şekilde 147 istasyon ile TUSAGA-Aktif GNSS ağı kurulumu gerçekleştirilmiştir. Daha sonrasında ise tesis edilen yeni istasyonlar ile bu sayı 159'a çıkarılmıştır. Ağ, Tapu ve Kadastro Genel Müdürlüğü (TKGM) ve Harita Genel Müdürlüğü (HGM) tarafından işletilmektedir (URL-15).

Şekil 6'da TUSAGA-Aktif ağına ait istasyon haritası gösterilmektedir. İstasyonların hızları HGM tarafindan 2015 yılının 1. ayına kadar olan GPS gözlemlerinin incelenmesi ile hesaplanmıştır. Yapılan incelemede ağdan bağımsız hareket eden istasyonlar tespit edilerek sebepleri araştırılmıştır (Özdemir, 2016). Her bir istasyonda anlık olarak konum bilgileri ve atmosferik düzeltmeler hesaplandığından, kullanıcının seçeceği düzeltme modeli ile Denizcilik Radyo Teknik Komisyonu (Radio Technical Commission for Maritime, RTCM) veri iletim kanalı kullanılarak hassas konum bilgisi sağlanmaktadır. Bunun dışında, sistem atmosferin modellenmesi, tektonik hareketlerin incelenmesi gibi birçok bilimsel çalı̧mada kullanılmaktadır. 


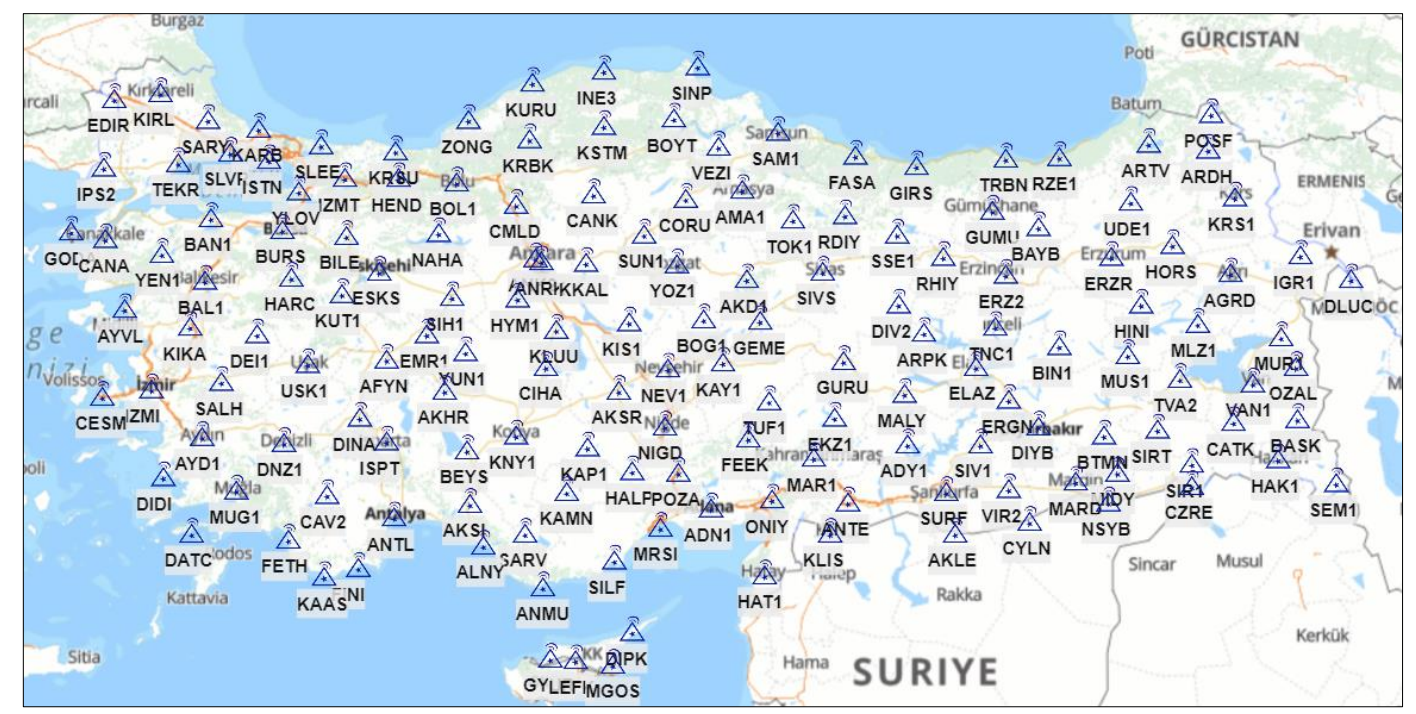

Şekil 6: TUSAGA-Aktif CORS ağı, Türkiye (URL-15).

TUSAGA-Aktif düzeltme yayımı ücretlidir. Aylık, yıllık ve bunların dışında belirli periyotlarda abonelik şartları mevcuttur. Üniversiteler ve diğer eğitim kurumlarında sadece kurum eğitim sınırları içerisinde ücretsizdir. Düzeltme yayımının dışında istasyonlara ait RINEX (Receiver Independent Exchange) verisi de kullanıcılar ile paylaşılmaktadır. 1 saniyelik veri ücretli olup, 30 saniyelik veri, düzeltme yayımına kayıtlı olan kullanıcılar için ücretsizdir. Yine eğitim kurumları için RINEX verisi paylaşımında belirli oranda indirim sağlanmaktadır. Deprem kuşağında bulunan Türkiye'de gerçekleşen 5 ve daha üzeri büyüklüklerdeki depremlerin ardından deprem bölgesinde bulunan TUSAGA-Aktif istasyonlarının verileri de ücretsiz olarak kullanıcılara sunulmaktadır (URL-15).

\subsection{Yerel CORS ağları}

Türkiye'de ülke genelini kapsayan TUSAGA-Aktif'in yanı sıra birçok yerel CORS ağı da mevcuttur. Çoğunluğu yerel yönetimler, az bir bölümü ise özel sektörün katılımı ile söz konusu yerel CORS ağlarının kurulum ve işletim faaliyetleri sürdürülmektedir. Bunların içinde, yerel yönetimler tarafından kurulan ilk yerel CORS ağı olan İstanbul Su ve Kanalizasyon İdaresi Uydulardan Konum Belirleme Sistemi (İSKİ UKBS) İstanbul genelinde 8 istasyon ile 2008 y1l sonunda kurulmuş, 2013 ve 2014 yıllarında 2 istasyonun daha ilave edilmesiyle istasyon sayısı 10'a çıkarılmıştır (Şekil 7). İstasyonlar arası mesafe yaklaşı 30 km'dir. İstasyon koordinatları dört adet Uluslararası GNSS Servisi (International GNSS Service, IGS) istasyonu temel alınarak hesaplanmıştır (Eroğlu, Taftalı, Gökdaş, \& Okur, 2017). 


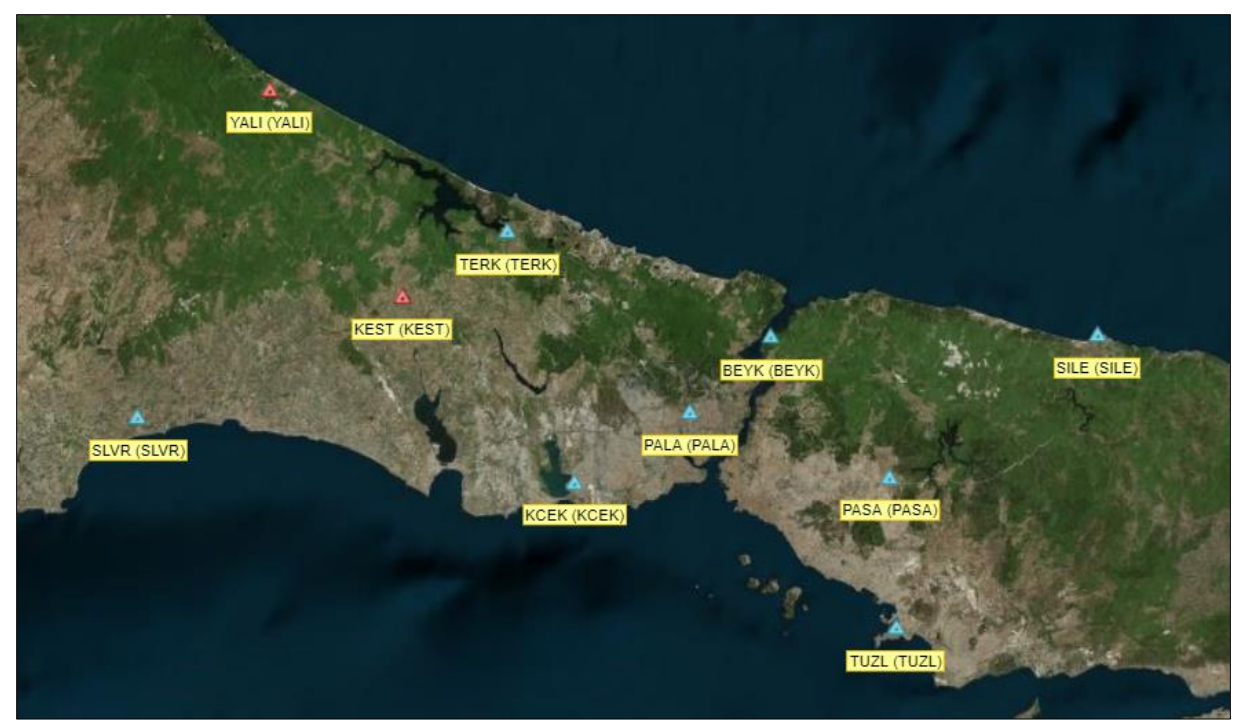

Şekil 7: ISKI UKBS ağı, Istanbul (URL-16).

İSKİ UKBS ağının kullanım alanı yerel yönetimlerin gereksinim duyduğu konum bilgisinin üretimi ile sınırlı kalmamış, farklı iş kollarındaki serbest mühendislik faaliyetlerinde ve proje çalışmalarında altlık olarak sürekli kullanılır hale gelmesiyle yaygınlaşmıştır.

İSKİ UKBS, CORS ağı tasarım ve işletme konusundaki tecrübelerini diğer yerel yönetimlerle paylaşarak, örnek olmuştur. Diğer yerel yönetimlerin bir kısmı da, 6 istasyonlu Sakarya Su ve Kanalizasyon İdaresi'nin (SASKİ) GNSS ağı ve 7 istasyonlu Bursa Su ve Kanalizasyon İdaresi'nin (BUSKİ) Sabit GNSS ağı (BUSAGA) örneklerinde olduğu gibi kendi yerel CORS ağlarını kurmuşlardır.

Tablo 2: Türkiye'deki mevcut ulusal ve yerel CORS ağları.

\begin{tabular}{cccc}
\hline Bölge & Kurum Adı & Cihaz marka & İstasyon Sayısı \\
\hline Türkiye-KKTC & TKGM-HGM & Trimble & 159 \\
Sakarya & Su ve Kanalizasyon İdaresi & Trimble & 6 \\
İstanbul & İSKİ & Topcon & 10 \\
Ankara & Ankara Büyükşehir Belediyesi & Topcon & 10 \\
Ankara & Tarım İşletmeleri G.M. & Topcon & 5 \\
Adana & Adana Su ve Kanalizasyon İdaresi & Topcon & 9 \\
Antalya & Antalya Elektrik Dağıtım & Topcon & 9 \\
Sivas & Çamlıbel Elektrik Dağıtım & Topcon & 9 \\
Bursa & Su ve Kanalizasyon İdaresi & Leica & 7 \\
Manisa & Büyükşehir Belediyesi & South & 5 \\
Aydın & Büyükşehir Belediyesi & South & 5 \\
Kocaeli & Su ve Kanalizasyon İdaresi & South & 5 \\
Muğla & Bodrum HKMO & South & 5 \\
Gaziantep & Büyükşehir Belediyesi & CHC & 4 \\
Malatya & Büyükş̧ehir Belediyesi & CHC & 5 \\
Denizli & Özel Harita Bürosu & Spectra & 4 \\
Kayseri & Kayseri Büyükşehir Belediyesi & Spectra & 3 \\
\hline & & & \\
\hline
\end{tabular}


Tablo 2'de Türkiye'de kurulan ulusal ve yerel CORS ağlarına ait bilgiler verilmiştir. Kurulumu gerçekleştiren kurum ya da sektör, kurulumun yapıldığı GNSS modeli ve faaliyet bölgesi bilgileri mevcuttur. Bunun yanında, ağ RTK ilkesi ile olmayıp tek bir istasyondan yayım yapan (single) RTK sistemleri de mevcuttur. Buna ait bilgi ise Tablo 3'te verilmişstir (Altın, 2021; Avc1, 2021; Özkan, 2021; Y1ldız, 2021; Yılmaz, 2021). Tablo 2'de Türkiye'de TUSAGA-Aktif'in dışında yerel olarak oluşturulmuş 16 adet CORS ağına ait bilgiler verilmiştir. Buna göre yerel oluşturulan CORS ağlarının toplam istasyon sayısı 101 adettir. Tablo 3’te ise yerel yönetimlerin ve özel sektörün single RTK yöntemi ile işlettiği sistemlerdeki toplam istasyon say1s1 72'dir.

Tablo 3: Türkiye'deki mevcut single RTK sistemleri.

\begin{tabular}{|c|c|c|c|c|c|}
\hline Bölge & Kurum Adı & $\begin{array}{c}\text { Cihaz } \\
\text { marka }\end{array}$ & Bölge & Kurum Adı & $\begin{array}{r}\text { Cihaz } \\
\text { marka }\end{array}$ \\
\hline Çorlu & Çorlu Belediyesi & Trimble & Van & Büyükşehir Belediyesi & Topcon \\
\hline Antalya & Antalya Su ve Atıksu İdaresi & Topcon & İzmir & Selçuk Belediyesi & South \\
\hline Kocaeli & İzmit Gaz & Topcon & Hatay & Özel Harita Bürosu & South \\
\hline Kütahya & Tavşanlı Belediyesi & Topcon & İzmir & Menderes Belediyesi & South \\
\hline Çanakkale & Çan Linyitleri İşletmesi & Topcon & Şanlıurfa & Şanlıurfa Belediyesi & South \\
\hline Kocaeli & İzmit Gaz (İZGAZ) & Topcon & Balıkesir & Balıkesir Belediyesi & South \\
\hline Amasya & Amasya Belediyesi & Topcon & Tokat & Erbaa Belediyesi & South \\
\hline Konya & Ereğli Belediyesi & Topcon & Antalya & Kaş Belediyesi & South \\
\hline İstanbul & Paksoy Ofis & Topcon & Trabzon & Vakfikebir Belediyesi & South \\
\hline Aksaray & Aksaray Belediyesi & Topcon & Maraş & Kahramanmaraş Belediyesi & South \\
\hline Adana & Ciner Kozan Soda Elektrik & Topcon & Aydin & Söke Belediyesi & South \\
\hline Eskişehir & Ciner Eti Soda & Topcon & Adapazarı & Özel Harita Bürosu & South \\
\hline Şırnak & Ciner Silopi Elektrik & Topcon & İstanbul & Kandilli (Statik-12 adet) & $\mathrm{CHC}$ \\
\hline Osmaniye & Osmaniye Belediyesi & Topcon & Samsun & Özel Firma & $\mathrm{CHC}$ \\
\hline Aydın & Söke Tarım & Topcon & Mersin & Özel Firma & $\mathrm{CHC}$ \\
\hline Şanlıurfa & Şanlıurfa Tarım & Topcon & Ankara & Özel Firma & $\mathrm{CHC}$ \\
\hline İzmir & PETKİM Petro Kimya & Topcon & Niğde & Ömer Halisdemir Üniversitesi & Spectra \\
\hline Konya & Büyükşehir Belediyesi & Topcon & Afyon & Kocatepe Üniversitesi & Spectra \\
\hline Denizli & Belediye & Topcon & İstanbul & Yıldız Teknik Üniversitesi & Spectra \\
\hline Gaziantep & Belediye & Topcon & Çanakkale & 18 Mart Üniversitesi & Spectra \\
\hline Samsun & Su ve Kanalizasyon İdaresi & Topcon & Trabzon & Karadeniz Teknik Üniversitesi & Spectra \\
\hline Malatya & Belediye & Topcon & İzmir & Tire Belediyesi & Spectra \\
\hline Mersin & Su ve Kanalizasyon İdaresi & Topcon & Kocaeli & Gölcük Belediyesi & Spectra \\
\hline Çorum & Çorum Belediyesi & Topcon & Aydın & Nazilli Özel Harita Bürosu & Spectra \\
\hline Konya & Ereğli Belediyesi & Topcon & Tekirdağ & Çerkezköy Özel Harita Bürosu & Spectra \\
\hline Diyarbakır & Diyarbakır Belediyesi & Topcon & Bursa & HKMO & Spectra \\
\hline Tokat & Belediye & Topcon & Antalya & Manavgat Özel Harita Büroları & Spectra \\
\hline- & Kandilli (Statik-7 adet) & South & İstanbul-Bursa & DOHAD (Statik) & Spectra \\
\hline
\end{tabular}




\section{Standartlar}

CORS ağlarının kurulumu ve işletilmesine yönelik dünya genelinde standartların geliştirilmesi için çalışmalar yapılmıştır. Örneğin NGS, yönettiği CORS ağları için bu standartları oluşturmuştur. Yerel CORS ağı kurucuları NGS tarafindan belirlenmiş standartlara ve kurallara uymaktadır. Bu sayede GNSS sinyal bozulmalarının en aza indirgenmesi ve GNSS konum belirleme kalitesinin en üst seviyeye çıkarılması amaçlanmıştır. NGS, ağ kapsama ihtiyaçlarına ve istasyonların iletişim gücüne dikkat ederek yerel ölçekte oluşturulan ağları bünyesine katmakta, standartları da yeni oluşan şartlara göre çeşitli zamanlarda güncellemektedir. NGS, ilk olarak 2005 yılında belirlemiş olduğu standartları en son 2018 y1lında güncellemiş̧tir (NGS, 2018). Bir başka örnek Avustralya'dır. Burada, Ölçme ve Harita Üretimi Hükümetler arası Komitesi (Intergovernmental Committee on Surveying and Mapping, ICSM) benzer şekilde bu standartları oluşturmuştur (ICSM, 2014).

Türkiye'de de CORS ağlarına yönelik standartlar geliştirilmektedir. Jeodezik çalışmalarda ulusal TUSAGA-Aktif ağının kullanımı için standartlar Büyük Ölçekli Harita ve Harita Bilgileri Üretim Yönetmeliği (BÖHHBÜY) ile belirlenmiştir (URL17). Türkiye'de yerel ölçekte oluşturulan ağların TUSAGA-Aktif ağına katılımı yasal bir dayanağı olmadığı için mümkün değildir. Bununla birlikte BÖHHBÜY hükümleri uyarınca tescile konu işlerde yerel CORS ağları kullanılabilmekte, bunun için bu ağların 2 yılda bir HGM tarafından tescili gerekmektedir. HGM, yerel ağ istasyonlarını, uydu görünürlük durumlarını, koordinat ve hız değerlerini inceleyerek belirlediği standartlara göre tescil edebilmektedir. Buna göre tek bir istasyondan tescile konu işlerde $5 \mathrm{~km}$ kapsamında RTK yapılabilmektedir (URL-15).

Ülkemizde yerel CORS ağlarının kurulması ve kullanımı konusunda kurumların temel aldığı normlar söz konusu olabilmektedir. Örneğin İSKİ UKBS ağının kurulumunda, istasyon yerlerinin belirlenmesinde İstanbul ili ve yakın çevresini kapsaması, iletişim altyapısının hazır olması, güvenlikli olması, enerji sıkıntısının yaşanmaması gibi hususlara dikkat edilmiş ve bu çerçevede İSKİ işletme binalarında karar kılınmıştır. Hangi binaların kullanılacağı hususunda ise referans istasyonunun kurulacağı yerde zeminin sağlamlığı, en yakındaki fay hattı, ulaşımın yılın kaç günü sağlanabildiği, alıcının bulunduğu kabin ile anten arasındaki kablonun uzunluğu, anten uydu yükseklik açısı için 5 derecenin üzerinde engel oluşturacak nesnelerin varlığı, GNSS sinyallerini etkileyecek yüksek gerilim hattı, telsiz, TV ve radar merkezinin varlığı, paratoner sisteminin mevcudiyeti gibi ölçütler araştırılmıştır. İşletimine ve kullanılmasına yönelik ise, iş sonu projelerinde, yaptırılan harita ölçüm ihalelerinde İSKİ UKBS ağı kullanımının da belirtildiği teknik şartnameler İSKİ tarafından her yıl düzenlenmektedir (İSKİ, 2021). Başka bir yerel CORS ağı örneği olan BUSAGA ağının kullanımı, paylaşımı ve uygulanmasına ilişkin ise BUSKİ Genel Müdürlüğü tarafından Harita Bilgi ve Belgeleri Kullanım Yönetmeliği hazırlanmıştır (BUSKİ, 2016).

\section{Yerel CORS ağlarının bilimsel çalışmalara katkıları ve entegrasyonu}

Yerel ölçekte oluşturulan CORS ağları haritacılık faaliyetleri dışında bilimsel çalışmalarda da fayda sağlamaktadır. İSKİ UKBS ağı örneğinde görüleceği gibi, ağın gerçek zamanlı düzeltme yayımı ve kesintisiz sağladığı statik veri, akademik ve bilimsel çalışmalarda da kullanılmış ve kullanılmaya devam etmektedir. İSKİ UKBS ağı verileri kullanılarak, proje ve araştırma faaliyetleri, makale, bildiri, bilimsel çalışmalar, lisans ve lisansüstü tez çalışmaları tamamlanmış ya da üzerinde çalışılmaya devam edilmektedir. Bu çerçevede İstanbul Kültür Üniversitesi, Yıldız Teknik Üniversitesi, İstanbul Teknik Üniversitesi, Ortadoğu Teknik Üniversitesi, TÜBİTAK Marmara Araştırma Merkezi (MAM) gibi akademik ve bilimsel kuruluşlara çalışmalarında destek amaçlı veri sağlanmıştır.

Yüksek lisans ve doktora düzeyinde yapılan lisansüstü tezlerde yerel CORS ağları ulusal ağlar ile beraber değerlendirilerek kabuk deformasyon analizleri ve bu ağlara ait hız kestirimleri yapılmıştır (Bak, 2014; Demirci, 2012; Kara, 2018; Özbey, 2017; Temiz, 2015). İnsansız hava aracı ile gerçekleştirilen fotogrametrik ölçümlerde yerel CORS ağı verileri kullanılmıştır. 
Bu sayede başlangıç dış yöneltme parametreleri belirlenmiş ve doğruluk analizleri yapılmıştır (Turan, 2019). Farklı senaryolar ile yerel CORS ağlarının bilimsel çalışmalara katkıları ve ulusal ağlara entegrasyonunun öneminin irdelendiği bir başka çalışmada kısa baz mesafelerinin özellikle tamsayı belirsizlik çözüm hızında ve yükseklik bileşeninde anlamlı etkileri ortaya konmuştur (Gökdaş, 2020). Yerel CORS ağları kullanılarak farklı GNSS ölçme tekniklerinin karşılaştırması yapılmıştır (Gündüz, 2013; Gürel, 2010; Ögüttcü, 2017; Öcalan, 2015; Sengü, 2012; Subaş1, 2011; Selbesoğlu, 2011; Pektaş, 2010). Yerel CORS ağı çözümleri ile elde edilen troposfer kestirimleri ile yüzey atmosferik değerler kullanılarak su buharı kestirimleri yapılmıştır (Gökdaş, 2014).

Lisansüstü tezlerin dışında birçok saygın akademik dergide makaleler yayınlanmış ve bilimsel paylaşım yapılmıştır. Bu hususta, yerel CORS ağı kullanılarak uydu görünürlüğü açısından düşük olan ormanlık alanlarda GNSS ölçme teknikleri analizi yapılmıştır (Pırtı \& Hoşbaş, 2019; Pırtı, 2020). Bağıl ve Hassas Mutlak Konum Belirleme (Precise Point Positioning, PPP) tekniklerini kullanan web tabanlı servislerin konum belirleme doğruluk analizleri yerel CORS ağı verileri ile analiz edilmiştir (Öcalan, Erdoğan, \& Tunalığlu, 2013). Yerel CORS ağının hız kestirimleri belirlenerek yerkabuğu hareketleri ile karşılaştırılmış ve web tabanlı servislerin hız kestirimindeki doğruluk analizleri yapılmıştır (Gökdaş \& Özlüdemir, 2021). Yerel CORS ağı verileri deformasyon analizi ve yapı sağlığı izleme çalışmalarında kullanılmıştır (Akpınar, Aykut, Dindar, Gürkan, \& Gülal, 2017; Gümüş \& Selbesoğlu, 2019). Yerel CORS ağı kullanılarak baz mesafesinin doğruluk, presizyon ve tamsayı belirsizlik çözüm oranı üzerindeki etkisi araştırılmış ve GNSS ölçmelerinde baz mesafesi ile ölçmelere ait varyans değeri arasında matematiksel bir model oluşturulmuştur (Gökdaş \& Özlüdemir, 2020a). Yerel CORS ağından türetilen troposfer gecikme değerleri ile su buharı kestirimleri yapılmış ve doğrulukları analiz edilmiştir (Gökdaş \& Özlüdemir, 2020b).

Bu çalışmalarla beraber ulusal ağların uluslararası entegrasyonu, yerel ağların ise ulusal ağlara nasıl entegre edilecekleri, ağların tasarım ilkelerinin ve nokta yoğunluğunun ne olması gerektiği tartışılmaya devam edilmektedir (Doğan, Ergintav, Çetin, Özdemir, \& Çakır, 2017; Kenyeres vd., 2019). Bu konuda geliştirilecek çözümler hem kaynakların verimli kullanılması hem de ağdan beklenen performansın güvence altına alınması açısından önemlidir.

Önceki bölümde sunulan Tablo 2 ve Tablo 3'te görüleceği üzere, Türkiye'de yerel yönetimler ve özel işletmeler tarafindan bağımsız olarak işletilen birçok yerel ağ mevcuttur. Ancak bu ağların birbirleri ile bilgi paylaşımı kısıtlı olup entegre edilebilmiş değildirler. Mevcut ağlardan en üst düzeyde fayda sağlanması amacı ile standartlarının merkezi bir otorite tarafından belirlenip denetlenmesi ve entegrasyonlarının sağlanması gerekmektedir. Önceki bölümde belirtilen BÖHHBÜY'deki belirlenmiş standartların gereksinimleri karşlayacak nitelik ve içeriğe sahip olacak şekilde geliştirilmesi önem taşıyan bir konudur. Bu çerçevede jeodezik faaliyetler için yerel CORS ağı başlı̆̆ının düzenlenmesi ve yerel ağların TUSAGA-Aktif ağına entegrasyonu konusu da Türkiye jeodezi topluluğu ve sorumlu kurumlar tarafindan ele alınması gereken güncel bir başlıktır. Bu hedef bu ağların hem pratik haritacılık faaliyetlerinde hem de bilimsel çalışmalarda daha etkin kullanılabilmesi için önerilmektedir.

Bu hususta, özellikle İSKİ UKBS ağı özelinde yapılan uygulamalar, yerel ağların ulusal ağlara entegrasyonunun ne derece önemli olduğunu ön plana çıkarmıştır. Yerel CORS ağlarının ulusal TUSAGA-Aktif ağına entegrasyonu ile nokta yoğunluğunun artırılacağı ve geometrinin güçlendirilmesi ile elde edilen çözüm kalitesinin iyileştirileceği değerlendirilmektedir. 


\section{Sonuçlar}

$\mathrm{Bu}$ çalışma ile farklı ülkelerde ulusal düzeyde gerçekleştirilen CORS ağı projelerine ve geliştirilen standartlara ilişkin örnekler verilmiş, Türkiye'deki mevcut durum ele alınmıştır. Bu hususta TUSAGA-Aktif ağı istasyon yoğunluğunun diğer verilen örneklerdeki ülkelere ait CORS ağlarındaki nokta sıklığı ile karşılaştırıldığında görece düşük olduğu görülmüştür. Bu çalışmada TUSAGA-Aktif ağının yanı sıra hem yerel yönetimler hem de özel sektör tarafından geliştirilmekte olan yerel CORS ağlarına ilişkin istatistiksel veriler paylaşılmıştır. Özellikle İSKİ UKBS yerel CORS ağı özelinde yapılan öğretim, araştırma, bilimsel çalışmalar incelenmiş ve ulusal ağa entegrasyon konusu değerlendirilmiştir. Özetle, kurulan yerel CORS ağlarının istasyonlar arası baz mesafesini kısalttığı, bunun da pratik haritacılık faaliyetlerinde konum belirleme doğruluğunu ve çözüm hızını artırdığına dikkat çekilmiştir. Bilimsel çevrelerde yerel CORS ağlarının entegrasyonunun yapılan çalışmalarda kısıtlı da olsa sağlandığı, gerek ulusal gerekse yerel CORS ağları verilerinin birlikte değerlendirildiği çalışmaların yapıldığı görülmektedir. Bu çalışmalar da entegrasyonun sağlayacağı iyileştirici katkıları ortaya koymaktadır. Yerel CORS ağlarını işleten kurumların bilgi paylaşımlarını artırmasının sözü edilen kısıtlılığı büyük oranda ortadan kaldıracağı ifade edilebilir. Pratik haritacılık faaliyetlerindeki entegrasyon sorununun ise Türkiye jeodezi topluluğunun önderliğinde sorumlu kurumlar tarafından geliştirilmesini önerdiğimiz CORS ağı kurulum ve işletim standartları ile aşılabileceği; BÖHHBÜY kapsamında jeodezik çalışmalar için yerel CORS ağlarının kullanımı başlığının düzenlenmesinin bu sürecin temel yasal altlığını oluşturacağı değerlendirilmektedir.

\section{Çıkar Çatışması Beyanı}

Yazar, bu çalışmada bilinen ilgili herhangi bir finansal veya finansal olmayan çıkar çatışması olmadığını beyan eder.

\section{Yazar Katkısı}

Ömer Gökdaş: Literatür taraması, Analiz ve yorumlama, Yazım, Veri toplama ve işleme. Mustafa Tevfik Özdemir: Fikir, Tasarım, Denetleme, Yazım, Makale değerlendirme, Analiz ve yorumlama.

\section{Kaynaklar}

Abd Rabbou, M., Abdelazeem, M., \& Morsy, S. (2021). Performance Evaluation of Triple-Frequency GPS/Galileo Techniques for Precise Static and Kinematic Applications. Sensors, 21(10), 3396.

Akpınar, B., Aykut, N.O., Dindar, A.A., Gürkan, K., \& Gülal, E. (2017). A ̆g RTK GNSS Yönteminin Yapı Sağlı̆̆ı İzleme Çalışmalarında

Kullanımı. Afyon Kocatepe Üniversitesi Fen ve Mühendislik Bilimleri Dergisi, 17(3), 1030-1040.

Altın, M. (2021). GNSS Teknik. Kişisel görüşme. 5 Mart 2021, İstanbul.

Avcı, Ö. (2021). Sistem A.Ş. Kişisel görüşme. 15 Mart 2021, İstanbul.

Bak, M. (2014). Jeodezik Çalışmalarla İzmit Körfezi ve Yakın Çevresi Kabuk Deformasyonlarının Belirlenmesi (Yüksek Lisans Tezi). İstanbul Teknik Üniversitesi, Fen Bilimleri Enstitüsü. İstanbul, Türkiye. YÖK'nin Tez Veri Tabanından erişildi. No: 356068.

BUSKİ. (2016). Harita Bilgi ve Belgeleri Kullanım Yönetmeliği. BUSKİ Genel Müdürlüğü. No:15.

Demirci, P. (2012). Yerel, Ulusal ve Uluslararası Sabit Referans İstasyonlarının Kabuk ve Yapısal Deformasyon Belirleme Amaçlı Tasarlanan Jeodezik Ağlara Entegrasyonu, Ölçme ve Değerlendirme Stratejileri. (Yüksek Lisans Tezi). İstanbul Teknik Üniversitesi, Fen Bilimleri Enstitüsü. İstanbul, Türkiye. YÖK'nin Tez Veri Tabanından erişildi. No: 315335.

Doğan, U., Ergintav, S., Çetin, S., Özdemir, A., \& Çakır, Z. (2017). Sürekli GNSS İstasyonları İçin Yeni Bir Yaklaşım: Marmara Entegre GNSS Ağı (MEGA). Türkiye Ulusal Jeodezi Komisyonu (TUJK) Bilimsel Toplantısı 2017. 
El-Mowafy, A., Fashir, H., Al Marzooqi, Y., Al Habbai, A., \& Babiker, T. (2003). Testing the Dubai virtual reference system (DVRS) National GPS-RTK network. In Satellite Navigation Systems (pp. 141-150). Springer, Dordrecht.

Eren, K., Uzel, T., Gulal, E., Yildirim, O., \& Cingoz, A. (2009). Results from a comprehensive Global Navigation Satellite System test in the CORS-TR network: Case study. Journal of Surveying Engineering, 135(1), 10-18.

Eroğlu S., Taftalı G., Gökdaş Ö., \& Okur Ö. (2017). Uydulardan Konum Belirleme Sistemi (UKBS). Türkiye Ulusal Jeodezi Komisyonu (TUJK) Bilimsel Toplantısı 2017.

Follestad, A. F., Clausen, L. B. N., Moen, J. I., \& Jacobsen, K. S. (2021). Latitudinal, Diurnal, and Seasonal Variations in the Accuracy of an RTK Positioning System and Its Relationship With Ionospheric Irregularities. Space Weather, 19(6).

Gökdaş, Ö. (2014). GPS Meteorolojisi: İstanbul için Bir Uygulama (Yüksek Lisans Tezi). İstanbul Teknik Üniversitesi, Fen Bilimleri Enstitüsü. İstanbul, Türkiye. YÖK'nin Tez Veri Tabanından erişildi. No: 349843.

Gökdaş, Ö. (2020). Yerel Jeodezik GNSS CORS Ağları ve Bilimsel Çalışmalara Katkıları: İSKİ UKBS Örneği, (Doktora Tezi). İstanbul Teknik Üniversitesi, Fen Bilimleri Enstitüsü. İstanbul, Türkiye. YÖK'nin Tez Veri Tabanından erişildi. No: 652824.

Gökdaş, Ö., \& Özlüdemir, M. T. (2020a). A variance model in NRTK-based geodetic positioning as a function of baseline length. Geosciences, 10(7), 262.

Gökdaş, Ö., \& Özlüdemir, M. T. (2020b) Effect of altitude and distance on zenith tropospheric delay and integrated water vapour estimations in a local GNSS CORS network. Jeodezi ve Jeoinformasyon Dergisi, 8(1), 72-83.

Gökdaş, Ö., \& Özlüdemir, M. T. (2021). Velocity estimation performance of GNSS online services (APPS and AUSPOS). Survey review, 53(378), 280-288.

Gümüş, K., \& Selbesoğlu, M. O. (2019). Evaluation of NRTK GNSS positioning methods for displacement detection by a newly designed displacement monitoring system. Measurement, 142, 131-137.

Gündüz, A.M. (2013). Klasik RTK ve ă̆-RTK Yöntemlerinin Karşılaştırılması (Yüksek Lisans Tezi). Selçuk Üniversitesi, Fen Bilimleri Enstitüsü. Konya, Türkiye. YÖK'nin Tez Veri Tabanından erişildi. No: 335381.

Gürel, N. (2010). Yapılaşmış ve Ağaçlık Bölgelerde Tek Sabit Referans İstasyonunun Kullanılabilirliğinin İncelenmesi (Yüksek Lisans Tezi). Yıldız Teknik Üniversitesi, Fen Bilimleri Enstitüsü. İstanbul, Türkiye. YÖK'nin Tez Veri Tabanından erişildi. No: 259788.

ICSM. (2014). Guideline for Continuously Operating Reference Stations.

İSKİ. (2021). İ̧ Sonu Projeleri Teknik Şartnamesi. İstanbul Su ve Kanalizasyon İdaresi. No: H.21.10.3.1.

Kahveci, M. (2009). Gerçek Zamanlı Ulusal Sabit GNSS CORS Ağları ve Düşündürdükleri. Jeodezi ve Jeoinformasyon Dergisi, (100), $13-20$.

Kara, İ. (2018). Orta Marmara Fayının Kinematiğinin GPS Ölçmeleriyle İzlenmesi. (Yüksek Lisans Tezi) İstanbul Teknik Üniversitesi, Fen Bilimleri Enstitüsü. İstanbul, Türkiye. YÖK'nin Tez Veri Tabanından erişildi. No: 511483.

Kenyeres, A., Bellet, J. G., Bruyninx, C., Caporali, A., De Doncker, F., Droscak, B., Duret, A., Franke, P., Georgiev, I., Bingley, R., Huisman L., Jivall, L., Khoda, O., Kollo, K., Kurt, A. I., Lahtinen, S., Legrand, J., Magyar, B., Mesmaker, D., Morozova, K., Nagl, J., Özdemir, S., Papanikolau, X., Parseliunas, E., Stangl, G., Ryczywolski, M., Tangen, O. B., Valdes, M., Zurutuza, J., \& Weber, M. (2019). Regional integration of long-term national dense GNSS network solutions. GPS Solutions, 23(4), 1-17.

Miyahara, B. (2016). GEONET, CORS Network of Japan. Geospatial and GNSS CORS Infrastructure Forum. Kuala Lumpur - Malaysia. NGS, (2018). Guidelines for New and Existing Continuously Operating Reference Stations (CORS).

Öcalan, T., Erdoğan, B., \& Tunalıoğlu, N. (2013). Analysis of web-based online services for GPS relative and precise point positioning techniques. Boletim de ciencias geodesicas, 19(2), 191-207.

Öcalan T. (2015). GNSS Ağlarında GPS Hassas Nokta Konumlama (GPS-PPP) Tekniği Yaklaşımlı Çözümler (Doktora Tezi). Yıldız Teknik Üniversitesi, Fen Bilimleri Enstitüsü, İstanbul, Türkiye. YÖK'nin Tez Veri Tabanından erişildi. No: 414154.

Öğütcü, S. (2017). A ̆ Bazlı RTK Tekniklerinin (VRS, FKP, MAC) Baz Uzunluğu ve Epok Sayısına Bağll Doğruluk ve Duyarlık Modellerinin Oluşturulması Üzerine Bir Çalışma (Doktora Tezi). Necmettin Erbakan Üniversitesi, Fen Bilimleri Enstitüsü. Konya, Türkiye. YÖK'nin Tez Veri Tabanından erişildi. No: 493842.

Özbey, V. (2017). Orta Marmara Fayının Kinematiğinin GPS Ölçmeleriyle Belirlenmesi (Yüksek Lisans Tezi). İstanbul Teknik Üniversitesi, Fen Bilimleri Enstitüsü. İstanbul, Türkiye. YÖK'nin Tez Veri Tabanından erişildi. No: 467206.

Özdemir, S. (2016). TUSAGA ve TUSAGA-Aktif istasyonlarının hassas koordinat ve hızlarının hesaplanması üzerine. Harita 
Dergisi, 155, 53-81.

Özkan, K. (2021). Paksoy Hizmetler. Kişisel görüşme. 10 Mart 2021, İstanbul.

Pektaş, F. (2010). Gerçek Zamanlı Ulusal ve Yerel Sabit GNSS Ağlarına Dayalı Kinematik Konumlama (TUGASA-Aktif - ISSKİ-UKBS Ağlarının Yerel Ölçekte Karşılaştırılması) (Yüksek Lisans Tezi). Yıldız Teknik Üniversitesi, Fen Bilimleri Enstitüsü. İstanbul, Türkiye. YÖK'nin Tez Veri Tabanından erişildi. No: 295706.

Pirt1, A. (2020). Millimeter Level Accuracy Point Positioning in Woodland Area by Using Hybrid Method. Forestry Ideas. Vol: 26, No: 1, (59), 119-131.

Pırt1, A., \& Hoşbaş, R. G. (2019). Role of CORS RTK (Network RTK) Mode Measurements in Determination of the Forest Boundary: A Case Study of ISKI-CORS. Forestry Ideas. Vol: 25, No: 2, (58), 394-403

Prochniewicz, D., Szpunar, R., Kozuchowska, J., Szabo, V., Staniszewska, D., \& Walo, J. (2020). Performance of Network-Based GNSS Positioning Services in Poland: A Case Study. Journal of Surveying Engineering, 146(3).

Schwieger, V. (2012). An Example of Terrestrial Reference Frame Realisation: Germany. IAG/FIG Commission 5/ICG Technical Seminar. Rome, Italy

Selbesoğlu, M.O. (2011). GNSS Ağlarından Üretilen Sanal Referans İstasyonu (VRS) Verilerinin Kalite Kontrolü ve Doğruluk Araştırmast (Yüksek Lisans Tezi). Yıldız Teknik Üniversitesi, Fen Bilimleri Enstitüsü. İstanbul, Türkiye. YÖK'nin Tez Veri Tabanından erişildi. No: 297164.

Sengü, M.Ö. (2012). Yerleşim Alanlarında CORS Yönteminin Kadastral Ölçmelerde Uygulanabilirlik Analizi (Yüksek Lisans Tezi). Yıldız Teknik Üniversitesi, Fen Bilimleri Enstitüsü. İstanbul, Türkiye. YÖK'nin Tez Veri Tabanından erişildi. No: 322675.

Subaşı, H.K. (2011). Internet Tabanlı GPS Değerlendirme Servislerinin Doğruluk ve Performans Analizi: İstanbul Örneği (Yüksek Lisans Tezi). İstanbul Teknik Üniversitesi, Fen Bilimleri Enstitüsü. İstanbul, Türkiye. YÖK'nin Tez Veri Tabanından erişildi. No: 307116.

Temiz, H.Ş.P. (2015). ISSKI UKBS Ăğ İstasyonlarının Zamansal Yer Değişimlerinin İncelenmesi (Yüksek Lisans Tezi). İstanbul Teknik Üniversitesi, Fen Bilimleri Enstitüsü. İstanbul, Türkiye. YÖK'nin Tez Veri Tabanından erişildi. No: 389396.

Tsuji, H., Kawamoto, S., \& Abe, S. (2018). Application of GNSS CORS for Precise Positioning and Earthquake Research in Japan. ICG Working Group D Reference Frames, Timing and Applications. Xi'an, China

Turan, E. (2019). Comparison of Satellite Positioning Techniques on Unmanned Aerial Vehicle Based Photogrammetry (Yüksek Lisans Tezi). İstanbul Teknik Üniversitesi, Fen Bilimleri Enstitüsü. İstanbul, Türkiye. YÖK'nin Tez Veri Tabanından erişildi. No: 613291.

Uzel, T., Eren, K., Gülal, E., Dindar, A.A., Tiryakioğlu, İ., \& Yılmaz H. (2011). TUSAGA Aktif(CORS $\neg$ TR) Verileri ile Tektonik Plaka Hareketlerinin İzlenmesi. TMMOB Harita ve Kadastro Mühendisleri Odası 13. Türkiye Harita Bilimsel ve Teknik Kurultayı. 18-22 Nisan 2011, Ankara.

Yayla, G., Van Baelen, S., Peeters, G., Afzal, M. R., Catoor, T., Singh, Y., \& Slaets, P. (2020). Accuracy Benchmark of Galileo and EGNOS for Inland Waterways. In Proceedings of the International Ship Control Systems Symposium (iSCSS), Delft, The Netherlands (pp. 6-8).

Y1ldız, S. (2021). Graftek A.Ş. Kişisel görüşme. 20 Mart 2021, İstanbul.

Yılmaz, M. (2021). Geomatik Hizmetler. Kişisel görüşme. 1 Mart 2021, İstanbul.

URL-1: NGS, https://catalog.data.gov/dataset/national-geospatial-data-asset-ngda-continuously-operating-reference $\% 20$ stations-cors $\% 20$ (Erişim Tarihi: 1 Şubat 2021)

URL-2: SAPOS GNSS ağı. http://www.adv-online.de/Products/SAPOS/, (Erişim Tarihi:2 Şubat 2021).

URL-3: Dubai (BAE) DVRS GNSS ağı. https://www.dm.gov.ae/survey-department/dubai-virtual-reference-station/, (Erişim Tarihi: 16 Haziran 2021).

URL-4: Belçika FLEPOS GNSS ağı. http://gnss.be/networks_tutorial.php, (Erişim Tarihi: 17 Haziran 2021).

URL-5: İsveç SWEPOS GNSS ağı. https://www.gsc-europa.eu/news/galileo-in-the-permanent-cors-network-in-sweden-a-success-story, (Erişim Tarihi: 17 Haziran 2021).

URL-6: Hollanda NETPOS GNSS ağı. https://www.nsgi.nl/netpos, (Erişim Tarihi: 18 Haziran 2021).

URL-7: Birleşik Kralık OS NET GNSS ağı. https://www.ordnancesurvey.co.uk/business-government/tools-support/os-net/positioning, (Erişim Tarihi: 20 Haziran 2021).

URL-8: Suudi Arabistan KSA-CORS GNSS ağı. https://www.gasgi.gov.sa/En/Products/Geodesy/Pages/KSA-CORS.aspx, (Erişim Tarihi: 
19 Haziran 2021).

URL-9: PositioNZ GNSS ağı. https://www.linz.govt.nz/data/geodetic-services/positionz, (Erişim Tarihi: 2 Şubat 2021).

URL-10: NGS GNSS ağı istasyon haritası. https://geodesy.noaa.gov/CORS_Map/, (Erişim Tarihi: 2 Şubat 2021).

URL-11: https://fig.net/resources/proceedings/2013/2013_reference_frame_in_practice_comm5/1.4_geonet_imakiire.pdf, (Erişim Tarihi: 2 Şubat 2021).

URL-12: SAPOS GNSS ağı istasyon haritası. https://www.adbv-immenstadt.de/produkte/dienste/sapos/allgemeines.html, (Erişim Tarihi: 2 Şubat 2021).

URL-13: SWEPOS GNSS ağı istasyon haritas1. https://eurogeographics.org/wp-content/uploads/2018/04/14_National_report_Sweden.pdf, (Erişim Tarihi: 2 Şubat 2021).

URL-14: SATREF/CPOS GNSS ağı istasyon haritası. https://www.gps.gov/cgsic/meetings/2020/jensen.pdf, (Erişim Tarihi: 2 Şubat 2021 ). URL-15: TUSAGA-Aktif. https://www.tusaga-aktif.gov.tr/, (Erişim Tarihi: 2 Şubat 2021).

URL-16: İSKİ UKBS ağı. https://global.topnetlive.com/Admin/Turkey/Networks/ISKI/Stations, (Erişim Tarihi: 2 Şubat 2021).

URL-17: Büyük Ölçekli Harita ve Harita Bilgileri Üretim Yönetmeliği. https://www.mevzuat.gov.tr/MevzuatMetin/3.5.201811962.pdf, (Erişim Tarihi: 2 Şubat 2021). 